\title{
Brujas, caballeros y princesas en el aula de Educación Infantil: la base de datos TESO como fuente de reflexión sobre los estereotipos sexistas
}

\author{
Witches, Knights and Princesses in the Elementary Classroom: \\ The TESO Database as a Source of Reflection on Sexist \\ Stereotypes
}

\author{
Alicia Vara López \\ Universidad de Córdoba, España
}

\begin{abstract}
Resumen: Las bases de datos de teatro español clásico son utilizadas como recursos de gran valor para la investigación especializada, pero también pueden ser enfocados a la docencia. Este artículo ofrece un acercamiento a la herramienta Teatro Español del Siglo de Oro y una propuesta didáctica para trabajar el tema de los estereotipos sexistas en el Grado de Educación Infantil. Dada la importancia de la calidad y adecuación de los primeros contactos con la literatura, resulta imprescindible la existencia de profesionales de la enseñanza con pensamiento crítico, capaces de seleccionar materiales de valor estético que a la vez sean adecuados para las primeras etapas educativas.
\end{abstract}

Palabras clave: bases de datos, teatro del Siglo de Oro, didáctica de la literatura, estereotipos sexistas, literatura infantil.

Abstract: Databases of classical Spanish theater are valuable resources for specialized investigation, but they can also be used to research pedagogical practices. This article approaches the study of the research tool Teatro Español del Siglo de Oro with a didactic intent, exploring the theme of sexist stereotypes in Elementary Education. Given the importance of the quality and adaptability of the first contacts with literature in the classroom, it is essential that professional educators exercise critical thought, selecting material with aesthetic merit which is, at the same time, appropriate for the earliest stages of education.

Keywords: databases, Golden Age Theater, didactic of Literature, sexist stereotypes, children's literature.

\section{Introducción}

Es bien sabido que uno de los objetivos que persigue todo proyecto de investigación sobre teatro del Siglo de Oro es la difusión del patrimonio de textos dramáticos, ya sea por medio de ediciones y estudios sobre obras o autores, mediante congresos, seminarios, jornadas, festivales o a través de portales y herramientas en Internet que actualizan y aportan visibilidad a nuestros clásicos. El presente artículo pretende contribuir a dicho cometido mediante la construcción de un puente entre los recursos y materiales que utilizan estudiosos y estudiosas del teatro áureo en sus investigaciones y un 
colectivo estratégico en la labor de transmisión cultural: el futuro cuerpo docente de Educación Infantil, al que se le asigna la difícil tarea de introducir actividades literarias en las primeras etapas educativas. El conocimiento por parte de los maestros y las maestras de tópicos, símbolos, iconografía y personajes del Siglo de Oro facilita una posible transmisión de los mismos al aula de Educación Infantil con previa adaptación, lo cual aporta un enorme enriquecimiento en los recursos literarios, así como infinidad de posibilidades didácticas'.

En este caso, el teatro clásico servirá como fuente de inspiración para la definición del concepto de "estereotipos sexistas", tan rentable en los estudios actuales sobre literatura infantil2. La capacidad de identificación de los rasgos de género constantes en distintos personajes resulta imprescindible para ejercitar el pensamiento crítico necesario para la adaptación y filtración de materiales en las aulas de Educación Infantil.

Como herramienta principal se utilizará una base de datos muy rentable en investigación, el Teatro español de Siglo de Oro (TESO), que recopila un amplio conjunto de comedias de los siglos XVI y XVII, de gran valor cultural, histórico y artístico ${ }^{3}$. La propuesta didáctica que se ofrece a continuación nace como una respuesta a las necesidades concretas de la asignatura de Literatura Infantil y su Didáctica, impartida en el Grado en Educación Infantil (Facultad de Ciencias de la Educación) pero podría aplicarse también a otras titulaciones como el Grado en Educación Primaria, el Grado en Historia, el Grado en Historia del Arte o distintas Filologías, así como en estudios de Máster respectivos a las mismas.

Como se avanzaba, uno de los aspectos más estudiados en la actualidad a propósito de la literatura infantil es el contenido sexista de determinadas obras, que se va transmitiendo en forma de estereotipos de género desde la infancia más temprana y a menudo pasa desapercibido para el personal docente. En general, los numerosos trabajos publicados en esta línea de investigación exploran desde una perspectiva de género la literatura $u$ otras manifestaciones culturales destinadas a un público infantil, dado que se trata del material susceptible de llegar a los colegios y a los hogares, aquel que se debe testar y cuestionar. Este trabajo pretende ampliar el campo de análisis al teatro áureo, desde el convencimiento de que la lejanía temporal y genérica con respecto a los cuentos y álbumes ilustrados utilizados en la actualidad puede resultar valiosa y enriquecedora. Esta perspectiva histórica permitirá al alumnado indagar y reflexionar acerca del arraigo y omnipresencia de ciertos roles, constantes en los cuentos tradicionales, que forman parte también de la tradición literaria no específicamente infantil y, en general, de nuestro acervo cultural. El teatro español de Siglo de Oro, reflejo de la cosmovisión barroca, se

\footnotetext{
1 En esta misma línea véase la propuesta de adaptación de La vida es sueño en forma de cuento, dramatización y actividades (Vara López \& Vila Carneiro, 2017) o las ideas sobre la didáctica del teatro áureo referidas a la enseñanza de la literatura en la clase de ELE (Vila Carneiro, 2015).

2 Sirvan como ejemplo Davies, 1994; Cromer, Turín et. al, 1996; Rosal, 2008; Vintró, 2008; Colomer \& Olid, 2008; y Pastor, 2009-2010.

${ }^{3}$ En este caso, en aras de una búsqueda de homogeneidad alrededor de la estética barroca y de una simplificación de la actividad, se fijará la atención de manera exclusiva en las obras del siglo XVII.
} 
incorpora como una valiosa fuente de información a la que recurrir desde el aula de Literatura Infantil con el objetivo de obtener una visión diacrónica de dichos estereotipos y conocer hasta qué punto siguen operativos en la actualidad. Se selecciona el teatro clásico como material de análisis porque se trata de un producto literario complejo y diverso, que bebe de distintas tradiciones y contiene también en ocasiones rasgos folclóricos de tradición oral. No es objetivo de este trabajo indagar en las fuentes de la literatura infantil y sus conexiones textuales, aspecto muy estudiado ya, sino activar el pensamiento crítico del alumnado desde el presupuesto de que la presencia de estereotipos es transversal a diversas manifestaciones literarias y arranca desde la misma configuración de los personajes. Existen múltiples recursos vinculados a la literatura infantil y tratados a menudo en dicha asignatura, como bases de datos o portales en Internet, pero hasta el momento no se han rentabilizado herramientas vinculadas al teatro clásico que pueden contar con un gran valor educativo.

En relación con lo dicho hasta ahora, la propuesta didáctica que sigue contribuye a que se adquieran las siguientes competencias del Grado en Educación Infantil4:

Competencia Básica 3 (CB3): Que los estudiantes tengan la capacidad de reunir e interpretar datos relevantes (normalmente dentro de su área de estudio) para emitir juicios que incluyan una reflexión sobre temas relevantes de índole social, científica o ética.

Competencia Universidad 2 (CU2) Conocer y perfeccionar el nivel de usuario en el ámbito de las TIC.

Competencia Básica 4 (CB4): Que los estudiantes puedan transmitir información, ideas, problemas y soluciones a un público tanto especializado como no especializado.

Competencia Básica 5 (CB5): Que los estudiantes hayan desarrollado aquellas habilidades de aprendizaje necesarias para emprender estudios posteriores con un alto grado de autonomía.

Además, se facilitará la adquisición de las siguientes competencias específicas:

Competencia específica 3 (CE3): Diseñar y regular espacios de aprendizaje en contextos de diversidad que atiendan a las singulares necesidades educativas de los estudiantes, a la igualdad de género, a la equidad y al respeto a los Derechos Humanos.

Competencia específica 11 (CE11): Reflexionar sobre las prácticas de aula para innovar y mejorar la labor docente. Adquirir hábitos y destrezas para el aprendizaje autónomo y cooperativo y promoverlo en los estudiantes.

Por último, dentro de las competencias modulares, se contribuirá al logro de la siguiente: ${ }^{4}$ Tomo como referencia el caso de dicha titulación en la Universidad de Córdoba y aporto
textualmente las competencias. 
Comptetencia modular 52 (CM9.10): Adquirir formación literaria y en especial conocer la literatura infantil.

\section{Las bases de datos sobre teatro clásico de Siglo de Oro como recurso en investigación y didáctica}

Para el acercamiento rápido y eficaz a los materiales de teatro clásico resulta muy útil la adquisición de destrezas de tipo procedimental por medio de la familiarización con tecnologías que nacen de las últimas investigaciones sobre teatro áureo español, vinculadas a las nuevas estrategias de la investigación humanística. En el campo del Siglo de Oro existe una red de herramientas de gran utilidad que facilitan el acceso a bibliografía primaria y secundaria, así como el análisis de una inmensa cantidad de materiales ${ }^{5}$. Dentro de este abanico de posibilidades, destaca una serie de bases de datos en la red (como TESO, Artelope o DICAT) que agrupan conjuntos de textos de naturaleza y contexto similar, sistematizados para posibilitar búsquedas. Muchos de los portales de esta naturaleza nacen de proyectos de investigación dirigidos por estudiosos $O$ estudiosas de reputado reconocimiento, en grupos como GRISO, PROTEO, GIC O PROLOPE6.

\subsection{Teatro Español del Siglo de Oro (TESO): un acercamiento a la herramienta}

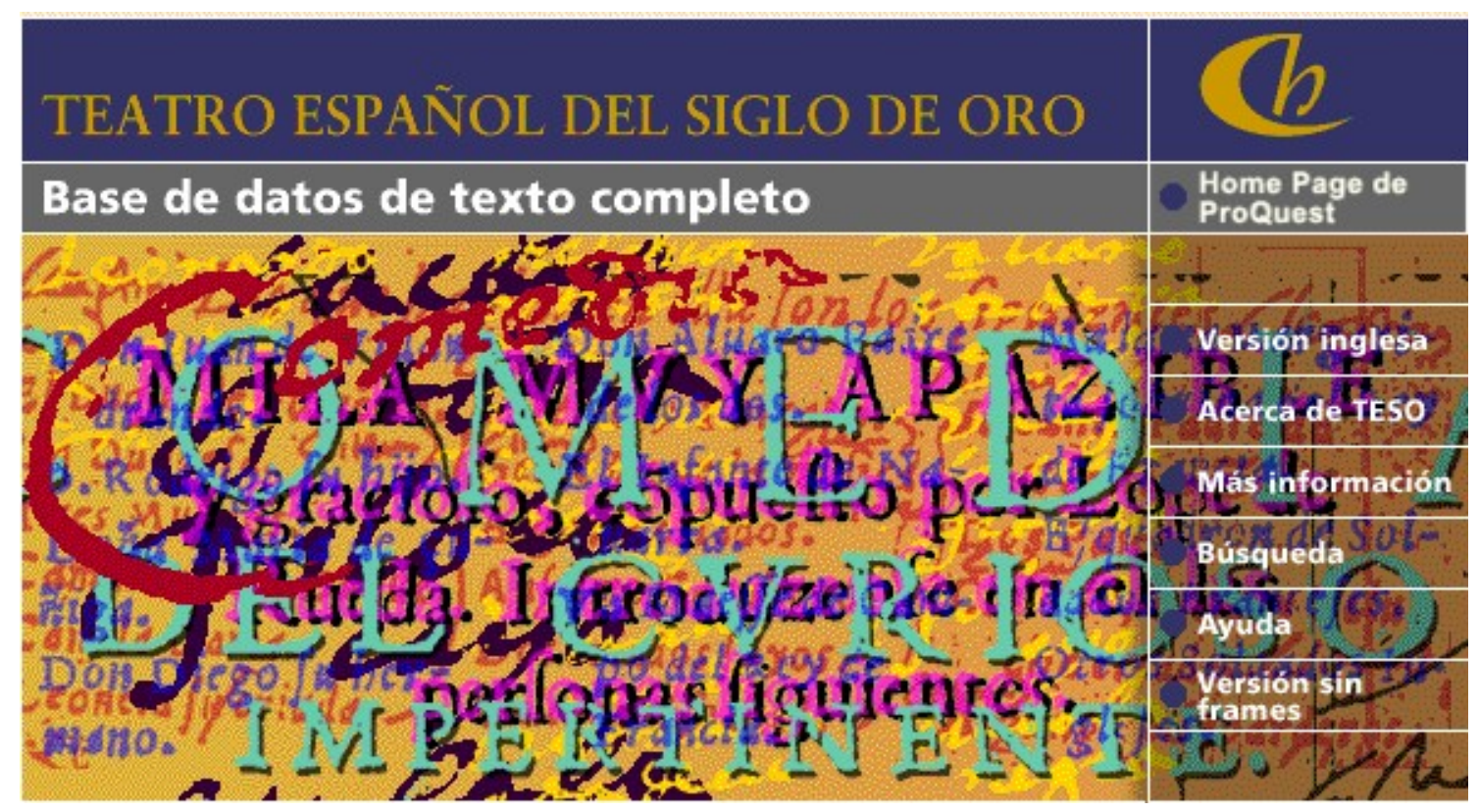

Imagen 1. Página de inicio del TESO: http://teso.chadwyck.com/

\footnotetext{
5 Sobre la presencia del teatro áureo en la red, además de los enlaces que se citarán a continuación, pueden verse los trabajos de Lucía Megías, 2007; Borja Rodríguez, 2004; Vega García-Luengos, 2013 o el número monográfico de la revista Teatro de palabras (2013), bajo la dirección de Joan Oleza, que ofrece numerosos estudios al respecto.

${ }^{6}$ En esta línea, el equipo de investigación DICAT, dirigido por Teresa Ferrer Valls, se ocupa del estudio de la documentación conservada sobre el teatro clásico español y de la aplicación de las nuevas tecnologías a este ámbito de estudio. Fruto de sus investigaciones es el Diccionario biográfico del teatro clásico español (DICAT) (2008). http://www.uv.es/dicat
} 
El Teatro Español del Siglo de Oro (TESO) ${ }^{7}$ es un portal, también publicado en formato CD-ROM, que alberga la base de datos de textos más completa del teatro áureo español, una herramienta de gran utilidad para cualquier investigación en el campo ${ }^{8}$. En concreto, resulta de obligada consulta para la realización de ediciones críticas y anotadas, pues aporta lugares comunes y coincidencias léxicas dentro de la obra de un mismo dramaturgo o entre distintos autores. EI TESO presenta por vez primera en Internet el conjunto de obras dramáticas fundamentales de los siglos XVI y XVII, con más de 800 piezas de 16 autores diferentes 9 : Pedro Calderón de la Barca, Guillén de Castro, Miguel de Cervantes Saavedra, Juan de la Cueva, Juan Bautista Diamante, Juan de Matos Fragoso, Agustín Moreto, Juan Pérez de Montalbán, Luis Quiñones de Benavente, Francisco de Rojas Zorrilla, Lope de Rueda, Juan Ruiz de Alarcón y Mendoza, Antonio de Solís, Tirso de Molina, Lope de Vega Carpio y Antonio Zamora ${ }^{10}$.

La ventana denominada "Tabla de contenidos" ofrece la relación de todas las obras incluidas, ordenadas alfabéticamente por autor y título. TESO reúne por primera vez ediciones que se encontraban dispersas por bibliotecas europeas y, como criterio de selección expuesto por el consejo editorial, se indica de manera explícita la utilización de ediciones recopiladas preferentemente por los propios autores o bajo su dirección, así como aquellas contemporáneas al dramaturgo, tratando de evitar (aunque no se consiga en todos los casos) las facticias. De hecho, siempre que es posible, se utilizan ediciones princeps. Se publican los textos completos con sus peculiaridades tipográficas y acompañados de los preliminares (aprobaciones, censuras, privilegios, etc.), al lado de una escueta información bibliográfica de cada uno de ellos, centrada en el contenido interno de los volúmenes. Los criterios de búsqueda son por palabras clave, por título, por personaje, por autor o por género. Gracias a la codificación SGML, es posible realizar complejas estrategias de búsqueda a través de la combinación de varias palabras mediante los operadores booleanos (Y, NO, YNO) y de proximidad (cerca / seguido), así como mediante variantes de una palabra, gracias a lo que en el proyecto se llama «truncamiento», para lo que se ponen las primeras letras de una palabra clave seguida de un asterisco (*). Además, existe la posibilidad de buscar en el texto completo o en secciones más concretas, conforme a los parámetros [1] texto, [2] título, [3] preliminares o [4] acotaciones. A la hora de visualizar los resultados se ofrecen dos opciones:

a) Obtener solo el contexto en el que aparece el texto buscado, extraído de la obra.

\footnotetext{
7 El manejo del corpus no es gratuito, sino que requiere una licencia. Sin embargo, las instituciones interesadas en Teatro Español del Siglo de Oro pueden solicitar, sin ningún compromiso, un período de prueba. Esta es la dirección web:

http://teso.chadwyck.com/

8 Para una descripción más pormenorizada del portal y del sistema de búsqueda puede verse Lucía Megías, 2007.

9 Para acceder al listado completo de obras puede verse la siguiente dirección electrónica: http://teso.chadwyck.com/frames/moreinfo/htxview?template=basic.htx\&content=infofram.htx 10 No sin reconocer el enorme esfuerzo que supone la incorporación de tantos autores y obras, cabe manifestar desde el presente estudio que resultaría muy valiosa la inclusión de alguna de las olvidadas autoras del teatro áureo español. Para un acercamiento al tema del silenciamiento que rodea a las dramaturgas del siglo XVII véase Ferrer, 1995.
} 
b) Acceder a la obra completa, desde la que aparece subrayado el texto buscado.

\subsection{EI TESO en el aula de Literatura Infantil y su Didáctica: una propuesta didáctica}

Como se avanzaba, el TESO es a menudo consultado en las investigaciones acerca del teatro áureo y resulta de enorme utilidad para la elaboración de ediciones críticas, pues ofrece la posibilidad de buscar una palabra 0 expresión y localizar el número de ocurrencias y los contextos en los que es empleada por un autor determinado, hecho que facilita la consideración o no de la misma como parte de su usus scribendi. Dicha estrategia ayuda a detectar en los textos errores o variantes externas al dramaturgo, así como a perfilar sus recursos verbales y su imaginario literario y simbólico. Por otro lado, es muy habitual el uso de dicha herramienta para la anotación de las obras, pues la aportación de pasajes paralelos resulta muy útil para la explicación de un término o secuencia. Además de todos estos usos más especializados, es sencillo realizar búsquedas sobre tópicos, personajes concretos, lugares, etc., lo cual posibilita un estudio panorámico del teatro español del Siglo de Oro.

La selección de dicha herramienta como instrumento para la didáctica de la literatura obedece en primer lugar a la propia familiaridad con la misma, a través de su versión en CD-ROM. Por ejemplo, en el Grupo de Investigación Calderón, donde me he formado como investigadora, es considerado un recurso indispensable para el acercamiento al dramaturgo y su utilidad está sobradamente comprobada a nivel personal y de equipo, tanto para la edición crítica como para la realización de estudios de tipo temático, simbólico o estilístico. El papel del profesorado de didáctica de la literatura en una facultad como la de Ciencias de la Educación está muy vinculado con la necesidad de actuar como puente que facilite que los conocimientos literarios que se enseñan en las facultades de Filología y aquellos sobre los que se trabaja desde los proyectos y grupos de investigación lleguen al cuerpo docente de magisterio y obtengan una rentabilidad en su futura práctica educativa. Por esta razón, resulta muy enriquecedora la utilización en el aula de recursos que se están empleando en los grupos de investigación dedicados al teatro clásico. En el caso que nos ocupa, el acercamiento del alumnado por medio del TESO a las características de ciertos personajes presentes en el teatro áureo y también en los cuentos tradicionales aportará una visión más completa acerca de la transmisión casi inconsciente de determinados estereotipos de género, un aspecto crucial en su formación docente.

La propuesta que se detallará a continuación facilita la toma de contacto con un producto cultural de valor incalculable, el teatro áureo, así como su divulgación por medio de actividades que pongan de manifiesto su utilidad y actualidad en las aulas universitarias ${ }^{11}$. Se resumirá a continuación la experiencia didáctica en su conjunto para después detallarla de manera

\footnotetext{
11 Vila Carneiro (2015: 13-14) hace alusión a las ventajas de tratar el teatro áureo, en su caso en el aula de ELE, y señala también las dificultades de enfrentarse a un lenguaje no contemporáneo, al verso como forma de expresión y a la distancia cultural. No obstante, la autora destaca que este tipo de obras se basan en la aparición de elementos recurrentes que, una vez dominados, facilitan la comprensión y acercamiento al texto.
} 
pormenorizada en siete sesiones de prácticas (de una hora cada una). El primer paso es seleccionar tres personajes tipo que constituirán el centro de la actividad y servirán para construir, por grupos y de manera cooperativa, un conocimiento que pretende ser estimulante, atractivo y significativo. Se trata de tres personajes perfectamente reconocibles y bien instalados en el imaginario colectivo desde la infancia: la princesa, la bruja y el caballero' ${ }^{12}$. La selección de los mismos obedece a su aparición reiterada en los cuentos infantiles, así como al alto grado de rasgos estereotipados que contienen, en relación con esquemas narrativos basados en la lucha del protagonista (caballero, héroe) contra el mal (muchas veces encarnado en una bruja), con la bonificación final de obtener a la princesa una vez resuelto el conflicto (objeto de deseo agraviado por la figura maligna) ${ }^{13}$. Será tarea del alumnado extraer y enumerar las características de cada uno de los tres personajes en los textos de teatro áureo analizados, establecer la relación existente entre los mismos, así como reflexionar acerca de la presencia en su configuración de estereotipos sexistas localizables también en el cuento tradicional. Para lograr estos objetivos generales, un tanto complejos en una formulación abstracta, se establecerán las siguientes sesiones de trabajo, correspondientes a prácticas semanales, en las que se desglosan actividades concretas y asequibles para estudiantes de Educación Infantil.

\subsection{Sesiones 1-3: Lluvia de ideas y búsqueda en el TESO}

Tras un breve adelanto de las tareas que ocuparán las próximas siete sesiones y la justificación del uso del teatro áureo para el estudio de estereotipos sexistas, se procederá a presentar la base de datos TESO. La familiarización del alumnado con las tecnologías facilitará la aproximación a la herramienta, mediante una definición de la misma con sus posibilidades de búsqueda. Seguidamente se pedirá una lluvia de ideas acerca de las asociaciones inmediatas que suscitan los sustantivos princesa, bruja y caballero, que pueden adoptar la función de adjetivos en algunos momentos, especialmente dotados de connotaciones de género.

A continuación, se formarán grupos (de unas cinco personas) y cada uno buscará en TESO uno de los tres términos, repartidos equitativamente. Las ventajas de esta tarea son la toma de contacto con la base de datos a nivel práctico, así como la visión panorámica del teatro áureo a través de la selección de pasajes extraídos del conjunto. El número de ocurrencias con las que se van a encontrar es bastante desigual: mientras que bruja aparece en

12 Como explica Subirats (2013: 61-62), el caballero se identifica con la tradicional figura del héroe, omnipresente en la literatura infantil muchas veces en forma de príncipe. Los héroes luchan cuando se sienten amenazados, con el objetivo de salvar a un pueblo o a una mujer. Para ellos lo crucial es defender a los débiles, extinguir el mal, dominar a su contrincante y liberar a los oprimidos, de forma que se conviertan en el elemento central de la masculinidad. Este papel conlleva matar y morir si fuera necesario, sin mostrar duda alguna. Seguir siendo el centro del universo tiene un alto peaje para el varón.

13 De acuerdo con Juana de José Prades (1963) una de las particularidades del teatro español de Siglo de Oro es la presencia de seis personajes-tipo: la dama, el galán, el gracioso, la criada, el rey y el padre. Si se atiende a los personajes objeto de esta experiencia didáctica, la princesa cuenta con características de la dama que define José Prades (hermosa y noble) y el caballero de nuestro estudio podría identificarse con el galán áureo (de buen talle, de origen noble, enamorado de la dama, valiente y generoso). 
TESO en 29 ocasiones y caballero en 10, princesa figura en 643 casos, con lo cual en este último caso sería aconsejable restringir la búsqueda a un autor determinado, como Calderón de la Barca, donde se localiza el término en 44 ocasiones. El trabajo que se les pide realizar consiste en seleccionar de entre todos los personajes caracterizados como «brujas», "princesas» o "caballeros»,, uno que les parezca llamativo y de interés, perteneciente a una obra concreta. Vélez y Bayo (2013: 99) aluden a la dificultad que aporta para la lectura el hecho de que las ediciones incluidas en TESO sean de tipo «semipaleológico», un hecho sin duda evitable. En efecto, esta particularidad complica el acceso a los textos por parte de un alumnado no especializado en literatura pero considero que no se trata de un obstáculo insalvable si se cuenta con el apoyo del profesorado, pues no es complicado habituarse a las peculiaridades gráficas y ortográficas, limitadas y recurrentes.

En definitiva, en esta primera fase (sesiones 1-3) el trabajo se basará en la localización, lectura, selección y síntesis de pasajes de la base de datos. El objetivo será que cada grupo se documente por medio de la herramienta sobre la bruja, caballero o princesa que elijan. Pongamos por caso que se opta por la princesa Argenis de Argenis y Poliarco de Calderón. En ese supuesto, tendrían que preparar un documento en el que se indique el autor y la obra a la que pertenece, así como información concreta y detallada sobre este personaje femenino que da título a la comedia. Cada grupo manejará las distintas posibilidades de búsqueda para analizar la presencia de Argenis en la obra de acuerdo con los siguientes aspectos generales:

1) Número de intervenciones en la obra (con voz propia)

2) Papel (activo o pasivo) desempeñado en la acción

3) Descripción a través de adjetivos

4) Espacios interiores o exteriores en los que aparece (por ejemplo: hogar o bosque)

Las tablas que siguen, de elaboración propia, servirán de soporte para la recopilación de datos acerca de los estereotipos sexistas asociados a cada personaje. A modo de ejemplo, las aplico al personaje calderoniano de Argenis:

\begin{tabular}{|l|l|}
\hline Datos del personaje & Argenis \\
\hline Nombre & Pasivo \\
\hline Papel (activo / pasivo) & 20 \\
\hline Edad aproximada & Princesa \\
\hline Profesión & $\begin{array}{l}\text { Forma parte de la realeza del reino } \\
\text { de Sicilia. Es hija del rey Meleandro. }\end{array}$ \\
\hline Clase social & $\begin{array}{l}\text { Palacio y quinta de retiro (jardines y } \\
\text { habitación propia). } \\
\text { domésticos. }\end{array}$ \\
\hline Ámbito de aparición (espacio) \\
$\begin{array}{l}\text { Número de intervenciones verbales } \\
\text { en las que toma la palabra }\end{array}$
\end{tabular}




\begin{tabular}{|c|c|c|c|}
\hline \multicolumn{2}{|l|}{ Descriptores del personaje } & \multirow[t]{2}{*}{ Sí } & \multirow{2}{*}{\begin{tabular}{|l} 
No \\
$X$
\end{tabular}} \\
\hline \multirow[t]{7}{*}{ Características psicológicas } & Rudo/a & & \\
\hline & Pasivo/a & $\mathrm{x}$ & \\
\hline & Astuto/a & & $x$ \\
\hline & Frágil & $\mathrm{X}$ & \\
\hline & Temeroso/a & $x$ & \\
\hline & Malvado/a & & $x$ \\
\hline & Inteligente & & $x$ \\
\hline \multirow[t]{4}{*}{ Características físicas } & Fuerte & & $x$ \\
\hline & Bello/bella & $\mathrm{X}$ & \\
\hline & Veloz & & $x$ \\
\hline & Ágil & & $x$ \\
\hline \multirow[t]{4}{*}{ Actividades que realiza } & Engaños & & $x$ \\
\hline & Encuentros amorosos & $\mathrm{X}$ & \\
\hline & Violencia & & $x$ \\
\hline & Aventura & & $x$ \\
\hline \multirow[t]{8}{*}{ Muestra } & Independencia & & $x$ \\
\hline & Dolor & $x$ & \\
\hline & Sensibilidad & $x$ & \\
\hline & Valentía & & $x$ \\
\hline & Ira & & $x$ \\
\hline & Competitividad & & $x$ \\
\hline & Seguridad & & $x$ \\
\hline & Curiosidad & & $x$ \\
\hline \multirow[t]{6}{*}{ Se le asignan papeles como } & Héroe/heroína & & $x$ \\
\hline & Guerrero/guerrera & & $x$ \\
\hline & Protector / protectora & & $x$ \\
\hline & Dominante & & $x$ \\
\hline & Triunfador/a & & $x$ \\
\hline & Sufridor/a & $\mathrm{x}$ & \\
\hline
\end{tabular}


Durante el proceso se podrán consultar, además del Diccionario de la Real Academia Española (DRAE) ${ }^{14}$, otras herramientas como el Diccionario de Autoridades, por medio de su versión online a la que se accede a través del Nuevo tesoro lexicográfico de la lengua española ${ }^{15}$, que aporta definiciones operativas en el siglo XVII'16, y el Tesoro de la lengua castellana o española, de Covarrubias ${ }^{17}$.

Con toda esta información elaborarán un informe que les servirá de material para la siguiente fase del trabajo.

\subsubsection{Sesiones 4-5: Construcción del personaje para la puesta en escena}

La segunda fase del trabajo, que abarca las sesiones 4 y 5 , consistirá en que un miembro del grupo se convierta en el personaje seleccionado y explique en primera persona a la clase sus características, tomando como base las tablas de recogida de datos antes cumplimentadas y el informe redactado en la sesión anterior. Tendrá la palabra una persona de cada grupo pero las demás contribuirán a preparar su guión y puesta en escena. Se trata de montar una pequeña representación teatral de entre 10 y 15 minutos en la que se dé voz a la princesa, bruja o caballero que hayan seleccionado. En estas sesiones se realizará un trabajo de síntesis y ordenación de la información obtenida para que pueda ser transmitida de una manera clara y ordenada. Puede tenerse en cuenta la acción de la comedia para la configuración del personaje pero lo esencial es detallar en primera persona las características recogidas en las tablas y los informes.

El recurso de la teatralización y el juego de roles facilita una puesta en común más atractiva que una simple lectura de informes. La necesidad de encarnar al propio personaje facilita un acercamiento al mismo y crea en el público un mayor interés por la información aportada. De esta manera, no solo se convierte en protagonista al personaje en cuestión, Argenis, en el ejemplo antes aportado, sino que es además el alumnado el que toma la palabra y se pone en el centro del escenario. De este modo, el conocimiento se construye de una manera activa y lúdica. Se deja abierta la posibilidad de utilizar disfraces o decorados sencillos, al gusto de cada grupo, con recursos de elaboración propia. La necesidad de volcar una información detallada en un molde dramático facilita el desarrollo de la creatividad, así como la necesidad de empatizar con el personaje seleccionado. Se trata de que el grupo reflexione acerca de cómo puede dar vida a su personaje y presentarlo al resto de la clase de una manera atractiva. Se animará al alumnado a la utilización de recursos como el humor o la interacción con el público.

\footnotetext{
14 http://dle.rae.es/

15 http://ntlle.rae.es/ntlle/SrvltGUILoginNtlle

16 De esta manera, podrán apreciar por ejemplo que normalmente las definiciones encontradas sobre el concepto de bruja suelen contener algún matiz negativo, en muchas ocasiones referido al aspecto físico de dicho personaje. Para un estudio del personaje de la bruja a lo largo de la tradición literaria véase Lisón, 1992; Perera \& Ramón Molina, 2003; Lara, 2008; Zaragoza \& Carrillos, 2003; Zamora, 2016.

17 http://fondosdigitales.us.es/fondos/libros/765/16/tesoro-de-la-lengua-castellana-o-espanola/
} 


\subsubsection{Sesión 6: Teatro en el aula}

Una vez preparado todo lo anterior, cada grupo utilizará sus 10-15 minutos para dar a conocer su personaje, de forma que irán desfilando princesas, caballeros y brujas que transmitirán en primera persona sus características y peculiaridades, desde una perspectiva de género. La brevedad de cada teatralización contribuye a que las sesiones sean dinámicas y variadas, de manera que se vayan plasmando distintas posibilidades de ser princesa, bruja o caballero y de representar dicha condición. Como se adelantaba, en cada grupo tomará la palabra una persona, pero los demás miembros estarán implicados en la caracterización del personaje, en la elaboración de decorados y en la posible utilización de recursos como la música. Esta puesta en común facilitará el conocimiento de un abanico de posibilidades dentro de los personajes seleccionados, así como la puesta de manifiesto de una serie de rasgos recurrentes en los mismos.

\subsubsection{Sesión 7: Reflexión crítica sobre los estereotipos tratados}

Una vez terminada la puesta en escena, en la sesión siguiente caballeros, princesas, brujas y el resto de la clase opinarán sobre los roles estereotipados que aparecieron en las representaciones y tratarán de vincularlos con aquellos que figuraban en los cuentos tradicionales con los que han crecido. En esta sesión final, en la que sigue manteniéndose la ficción en cuanto que los personajes seguirán caracterizados como tales, se pretende promover una reflexión crítica acerca de lo aprendido en la práctica. La sesión se estructurará en las siguientes partes, de forma que cada una ocupará la mitad del tiempo (30 minutos):

$1^{a}$. Los personajes, todavía caracterizados como tales, tomarán la palabra para expresar en primera persona su opinión o quejas sobre el papel que desempeñaron en sus respectivas obras. Por ejemplo, Argenis podría estar en desacuerdo con pasar toda la comedia en espacios controlados por el padre o indicar que además de ser bella también cuenta con otras características que no aparecen reflejadas en la comedia.

$2^{a}$. Como actividad final se pasará a relacionar la experiencia didáctica basada en el teatro de Siglo de Oro, ya completada, con la literatura infantil (en concreto, con los cuentos tradicionales). El objetivo general de todas las tareas realizadas con el apoyo del TESO era la reflexión acerca de la existencia de estereotipos sexistas en la literatura española y la definición de los mismos. Una sensibilización con esta mirada de género facilitará poder trabajar con la literatura infantil tradicional desde una óptica más responsable y coeducativa. La clase en su conjunto enumerará los rasgos constantes de brujas, princesas y caballeros y reflexionará acerca de si los estereotipos sexistas que fueron apareciendo en las representaciones están vigentes en la literatura infantil tradicional, a través del repaso por algunos de los cuentos de hadas donde figuran dichos personajes. Las preguntas que siguen pueden ayudar a iniciar la actividad: ¿ Cuáles son los estereotipos sexistas asociados a cada uno de los tres personajes? ¿Crees que dichos estereotipos están presentes en los cuentos tradicionales maravillosos de tu infancia (por ejemplo, 
en La bella durmiente, La Cenicienta o Blancanieves y los siete enanitos)? 18 ¿Tratarías esos mismos cuentos en el aula de Educación Infantil? En caso afirmativo, ¿qué tipo de modificaciones o matizaciones propones para evitar la transmisión de contenidos sexistas?

Una vez descritas las siete sesiones de trabajo, se puede afirmar que la propuesta didáctica descrita busca el alcance, por parte del alumnado, de los siguientes objetivos, relacionados de manera directa o indirecta con las competencias del Grado de Educación Infantil:

a) Conocer y valorar el patrimonio teatral clásico como fuente de información de tipo histórico, cultural y literario.

b) Manejar la base de datos TESO como herramienta de investigación.

c) Fijar el significado y connotaciones de las denominaciones «princesa», «bruja» y "caballero» en el contexto del teatro del Siglo de Oro y aportar una lectura de género.

d) Identificar en la literatura infantil la presencia de estereotipos sexistas, sobre la base de la actividad realizada con anterioridad.

\section{Conclusiones}

El teatro español de Siglo de Oro, como espejo de vidas, sentimientos, y experiencias humanas, puede considerarse una valiosa galería de estereotipos sociales y de género, susceptibles de ser explorados desde diversas perspectivas y conectados con la realidad contemporánea. En esta propuesta se destaca el valor didáctico para la Facultad de Ciencias de la Educación de una herramienta bien instalada en los proyectos de investigación sobre el teatro clásico: la base de datos TESO, que ofrece infinidad de posibilidades para el acercamiento a los textos teatrales de Siglo de Oro. La presentación de este recurso en la asignatura de Literatura Infantil permite al mismo tiempo enseñar estrategias para la exploración del legado literario clásico y utilizarlas en beneficio de la creación de una conciencia crítica y una visión de género, imprescindible para la tarea docente en las aulas de Educación Infantil.

En el contexto de la dramaturgia barroca, en la que confluyen movimiento, poesía y un cúmulo de referencias culturales y artísticas, los distintos roles masculinos o femeninos se engarzan en un aparato metafórico y simbólico propio, cuya exploración desde el siglo XXI está más que justificada, dada la lejanía cronológica y el interés estético de dichos materiales. La propuesta didáctica que se ha ofrecido persigue que el alumnado del Grado en Educación Infantil sea capaz de utilizar la base de datos TESO con el propósito de discernir y sistematizar una serie de directrices invisibles pero constantes que marcan en el teatro áureo las pautas de cuáles serían los roles y las posibilidades dramáticas de personajes tan centrales como la princesa, la bruja o el caballero. El manejo de dichos códigos no explícitos facilita también un mejor conocimiento del teatro del Siglo de Oro, y-más concretamente- de las relaciones existentes entre los personajes y sus posibles acciones en las tablas, sin olvidarse de la extrañeza que producirían en el auditorio posibles desvíos de la norma.

\footnotetext{
18 El tema de las distintas versiones de los cuentos, bastante complejo y que por ello excedería el límite de esta propuesta, se dejará para otra ocasión. En este caso se pedirá al alumnado que recuerde la versión que le llegó en su infancia de cada uno de los cuentos mencionados.
} 
En fin, el aula de Literatura Infantil y su Didáctica es un espacio óptimo para realizar este tipo de reflexiones y establecer un puente de encuentro entre el teatro áureo y la literatura destinada a un público infantil, donde se localizan rasgos estereotipados que van configurando una visión social de los géneros dicotómica y simplificada. Invitamos desde aquí a llenar las aulas universitarias con nuestros clásicos, a veces conmovedores, a veces complejos y perturbadores, pero siempre dotados de la capacidad de sorprender y fascinar. Reabramos, aunque sea en el particular escenario del aula, las puertas de los corrales de comedias para que desfilen ante nuestros ojos personajes, símbolos y universos capaces de inspirarnos en la tarea docente 0 , lo que es lo mismo, en la compleja necesidad de entender y a la vez cuestionar el mundo, el ser humano y sus pasiones.

\section{Bibliografía}

BORJA RODRÍGUEZ, M.J. (2004): "Recursos sobre literatura y teatro áureo en Internet" Estudios Humanísticos. Filología, 26, pp. 253-258.

COLOMER, T. \& I. OLID (2008): "Princesitas con tatuaje: Las nuevas caras del sexismo en la ficción juvenil". Textos de didáctica de la Lengua y de la Literatura, 51, pp. 55-67.

CROMER, S., A. TURÍN et al. (1996): ¿Qué ven los niños en los libros de imágenes? Respuestas sobre los estereotipos. París: Association Européenne du Côte des Filles. Recuperado de: http://www.fundaciongsr.es/pdfs/2encuesta.pdf

COVARRUBIAS OROZCO, SEBASTIÁN de (2006): Tesoro de la lengua castellana o española. DVD: Studiolum, eds. Ignacio Arellano y Rafael Zafra, Navarra: Vervuert. Consultado en http://fondosdigitales.us.es/fondos/libros/765/16/tesoro-de-la-lenguacastellana-o-espanola/

DAVIES, B. (1994): Sapos y culebras y cuentos feministas. Los niños de preescolar y el género. Madrid: Editorial Cátedra.

Diccionario de Autoridades (1726-1739). Ed. facsímil, 3 vols. Madrid: Gredos, 1999. Consultada en Nuevo tesoro lexicográfico de la lengua española. http://ntlle.rae.es/ntlle/SrvltGUILoginNtlle

FERRER VALLS, T. (1995): La ruptura del silencio: mujeres dramaturgas del siglo XVII. Mujeres: escrituras y lenguajes en la cultura Latinoamericana y Española. S. MATTALÍA \& M. ALEZA (eds.). Valencia: Universitat de València, pp. 91-108.

JOSÉ PRADES, J. de (1963): Teoría sobre los personajes de la comedia nueva, en cinco dramaturgos. Madrid: CSIC.

LARA, E. (2008): "El personaje de la bruja en Literatura Infantil". Revista de investigación teatral, 5, pp. 6-25.

LISÓN TOLOSANA, C. (1992): Las brujas en la historia de España. Madrid: Temas de Hoy. 
LUCÍA MEGÍAS, J.M. (2007): "Enredando con el teatro español de los Siglos de Oro en la Web: de los materiales actuales a las plataformas de edición". Signa, 17, pp. 1-30.

OLEZA SIMÓ, J. (dir.) (2013): Lope de Vega y el teatro clásico español: nuevas estrategias de conocimiento en humanidades. Teatro de Palabras. Revista sobre teatro áureo, 7 (número monográfico).

PASTOR, A.A. (2009-2010): "Roles y diferenciación de género en la literatura infantil". Revista Borradores, $10-11$, pp. 1-11.

PERERA SANTANA, A. \& E. RAMÓN MOLINA (2003): "Las brujas de Roald Dahl en la tradición literaria infantil". Canon, Literatura infantil y juvenil, y otras literaturas. A.G. CANO VELA \& C. PÉREZ VALVERDE (coords.). Las Palmas de Gran Canaria: Colección Estudios, pp. 513-521.

REAL ACADEMIA ESPAÑOLA: Diccionario de la lengua española. http://dle.rae.es/

ROSAL, M. (2008): "Semiótica de la soledad o la cancelación del síndrome de Cenicienta". ED.UCO Revista de Investigación Educativa, 3, 53-70.

SIMÓN PALMER, M.C. (ed.): Teatro Español del Siglo de Oro (base de datos TESO). Cambridge: ProQuest Information and Learning Company. http://teso.chadwyck.com/

SUBIRATS, M. (2013): Forjar a un hombre, moldear a una mujer. Barcelona: Editorial Aresta.

VARA LÓPEZ, A. \& Z. VILA CARNEIRO (2017): "Segismundo y su torre: la literatura áurea como recurso para el tratamiento de la integración en el aula de Educación Infantil". Tejuelo, 25, 161-188.

VEGA GARCÍA-LUENGOS, G. (2013): "El gran teatro del Siglo de Oro de la Red Mundial: realidades y proyectos". Teatro e Internet en la primera década del siglo XXI. J. ROMERA CASTILLO (ed.). Madrid: Verbum, pp. 70-96.

VÉLEZ SÁINZ, J. \& J.C. BAYO JULVE (2013): "El corpus electrónico de Teatro Breve Español (CORTBE): los autores dieciochescos". Teatro e Internet en la primera década del siglo XXI. J. Romera Castillo (ed.). Madrid: Verbum, pp. 97-107.

VILA CARNEIRO, Z. (2015): "Literature en SFL situations: Some ideas for teaching Spanish Golden Age theatre". Docencia e investigación. Número monográfico: Creativity, Gamification and Innovation in Second Language Teaching, 25, 2, pp. 11-25.

VINTRÓ, M. (2008): "Sexismo en la Literatura Infantil". Cuadernos de Literatura Infantil y Juvenil, 217, pp. 21-27.

ZAMORA CALVO, M.J. (2016): Artes Maleficorum. Brujas, magos y demonios en el Siglo de Oro. Madrid: Calambur.

ZARAGOZA CANALES, F. \& M.J. CARRILLOS LÓPEZ (2003): "Las brujas en los cuentos populares. Conjuros, pócimas y encantamientos". Canon, Literatura infantil y juvenil, y otras literaturas. A.G. CANO VELA \& C. PÉREZ VALVERDE (coords.). Castilla-La Mancha: Colección Estudios, pp. 31 1-321. 